\title{
Correlates of Smoking Cessation Among Filipino Immigrant Men
}

\author{
Gabriel M. Garcia · Romina A. Romero • \\ Annette E. Maxwell
}

Published online: 19 March 2009

(C) The Author(s) 2009. This article is published with open access at Springerlink.com

\begin{abstract}
A survey on tobacco use among 318 Filipino immigrant men aged 40-75 years was conducted in Los Angeles, California. Those who reported more English language use with their family, friends and neighbors $(\mathrm{OR}=1.31)$ and who lived in households with complete smoking prohibition $(\mathrm{OR}=3.82)$ were more likely to be successful in quitting smoking. Those who endorsed more positive beliefs on physical and social consequences of smoking $(\mathrm{OR}=0.69)$ and who had mostly smoking friends $(\mathrm{OR}=0.37)$ were less likely to be successful in quitting smoking. Our findings suggest that prohibiting smoking in households, creating social networks of nonsmokers, and education or counseling are important components of a smoking cessation intervention for Filipino immigrant men.
\end{abstract}

Keywords Smoking - Smoking cessation · Filipino American · Filipino immigrant · Men · Smoking cessation correlates

G. M. Garcia ( ()

Department of Health Sciences, College of Health \& Social Welfare, University of Alaska Anchorage, 3211 Providence Drive, Anchorage, AK 99508-4614, USA

e-mail: gabrieljmgarcia@uaa.alaska.edu

\section{R. A. Romero}

Joint Doctoral Program, Public Health (Health Behavior), San Diego State University/University of California, San Diego, San Diego, CA, USA

\section{A. E. Maxwell}

Division of Cancer Prevention \& Control Research, School of Public Health/Jonsson Comprehensive Cancer Center, University of California, Los Angeles, Los Angeles, CA, USA

\section{Introduction}

Over two million Filipinos live in the U.S., with more than half residing in California, making them the second largest Asian subgroup in both the nation and state [1]. In California, more Filipino men currently smoke (24\%) than Non-Hispanic whites (19\%), African Americans (22\%), and Hispanics (20\%) [2]. Among Filipinos, lung cancer is the leading cause of cancer-related deaths [3]. With many Filipinos in the U.S. dying prematurely from smoking, there is an urgent need for tobacco control intervention for this population.

Key to designing effective tobacco control programs is understanding the barriers to and facilitators of quitting. Studies have shown that smoking cessation is associated with being older, having higher levels of income and education, and being married $[4,5]$. Successful quitters also have more negative perceptions of smoking, more concerns regarding health effects $[2,5,6]$, and a stronger desire and motivation to quit smoking [4]. Initiating smoking at a later age, history of smoking less frequently, history of past quit attempts [4], cohabitating with non-smokers [2, 4, 6], and living in a household where smoking is prohibited $[5,6]$ have also been associated with quitting. With regards to Asian U.S. immigrants, Ma et al. found that men with higher levels of acculturation were more likely to be never or former smokers [7], while Ji and colleagues found the opposite among Korean men and women [6].

Literature is lacking on smoking behavior among Filipinos in the U.S. A recent study examined factors associated with current smoking among Filipino immigrant men in Los Angeles County, but it did not examine factors associated with successful smoking cessation [8]. For this study, we investigate the correlates of successful quitting among this particular population. 


\section{Methods}

Participants

Investigators partnered with several Filipino communitybased organizations in Los Angeles County and conducted a survey among 318 Filipino immigrant men aged 40-75 years from May 2004 to May 2005. The Institutional Review Board at the University of California, Los Angeles approved the research protocol. Details regarding recruitment, interview procedures, and the survey instrument have been described elsewhere [8]. Eighty-five percent of men approached completed the survey. This analysis was limited to a sub-sample of men who have ever tried quitting smoking $(N=184)$. All respondents in the sub-sample were born in the Philippines.

\section{Measures}

The outcome variable was successful quitting, defined as quitting smoking for at least a year, and independent variables included demographic characteristics, acculturation, smoking history, cognitive, and social and physical environmental items. Demographic characteristics included age, education, marital status, income, employment status, and health insurance status. Since respondents living in Filipino ethnic enclaves may use their native language often, regardless of their length of stay in the U.S., we measured acculturation using two items: (1) percent lifetime spent in the U.S. and (2) language use during family gatherings, with friends and neighbors. Three language use questions using a 5-point scale were combined into an index (Cronbach's $\alpha=0.64$ ) which ranged from five (mostly Tagalog, a measure of lower acculturation) to 15 (mostly English, a measure of higher acculturation).

Smoking history was assessed by asking about age of smoking initiation. Cognitive items included an 8-item index measuring the respondents' knowledge of the health effects of smoking (Cronbach's $\alpha=0.64$, range 0-8) and a 12-item index measuring the respondents' beliefs on the social and physical benefits of smoking (Cronbach's $\alpha=0.85$, range $0-12$ ). A high knowledge index score indicates a high level of knowledge on the health effects of smoking, while a high belief index score indicates more positive belief toward the physical and social benefits of smoking. Details regarding knowledge and beliefs items have been reported previously [8]. Social environment was assessed by asking about smoking among friends and household members. Physical environment was assessed by asking respondents about smoking rules in their homes.
Analysis

We analyzed our data using SPSS 11.5 [9]. We assessed whether there were significant difference in demographic characteristics, smoking history, acculturation, cognitive, and environmental characteristics between successful and unsuccessful quitters of smoking, using chi-square test for categorical variables and $t$-tests for continuous variables. We checked for collinearity between independent variables using a correlation matrix; seeing there were none, we entered all independent variables into a logistic regression analysis to predict successful quitting. Twenty-one cases were missing in the regression, and they were addressed by listwise deletion. We found that the Hosmer and Lemeshow goodness-of-fit in our regression model showed no significant difference between the observed and modelpredicted values ( $P$-value is $>0.05$ ), indicating the model's estimates fit the data at an acceptable level.

\section{Results}

Bivariate analyses showed significantly higher proportions of successful quitters had an annual household income of $\$ 50,000$ per year or more, had health insurance, and lived in a household where smoking was completely prohibited as compared to unsuccessful quitters. In addition, successful quitters were more likely to use English with family and friends, were less likely to endorse positive beliefs on physical and social consequences of smoking, and only about $20 \%$ stated that most of their friends smoked, as compared to more than $40 \%$ among unsuccessful quitters (see Table 1).

Logistic regressions showed four items to be independently associated with smoking cessation. Those who reported using mostly English with their friends, family, and neighbors $(\mathrm{OR}=1.31)$ and those who lived in households with complete smoking prohibition $(\mathrm{OR}=3.82)$ were more likely to be successful in quitting. In contrast, those who endorsed more positive beliefs on physical and social consequences of smoking $(\mathrm{OR}=0.69)$ and those who had mostly smoking friends $(\mathrm{OR}=0.37)$ were less likely to be successful in quitting.

\section{Discussion}

To our knowledge, this is the first report of predictors of smoking cessation among Filipino immigrant men. Although bivariate analyses showed that successful quitters were more likely to have higher income and health insurance, these relationships were no longer statistically 
Table 1 Bivariate analysis of the sample and logistic regression predicting successful quitting in smoking

\begin{tabular}{|c|c|c|c|c|c|}
\hline Characteristics & $\begin{array}{l}\text { Unsuccessful } \\
\text { quitters } \\
(N=81) \\
\text { Percent or } \\
\text { Mean } \pm \text { S.D. }\end{array}$ & $\begin{array}{l}\text { Successful } \\
\text { quitters } \\
(N=103) \\
\text { Percent or } \\
\text { Mean } \pm \text { S.D. }\end{array}$ & $P$-value ${ }^{\mathrm{a}}$ & $\begin{array}{l}\text { OR: } \\
\text { Successful } \\
\text { quitting }\end{array}$ & $\begin{array}{l}95 \% \\
\text { Confidence } \\
\text { interval }^{\mathrm{b}}\end{array}$ \\
\hline \multicolumn{6}{|l|}{ Demographics } \\
\hline Age & 57.3 years \pm 9.9 & 59.3 years \pm 10.2 & N.S. & 1.02 & $0.97-1.07$ \\
\hline$\geq$ College graduate (vs. $<$ College graduate) & $42.0 \%$ & $54.4 \%$ & N.S. & 1.01 & $0.42-2.48$ \\
\hline Married/living with a partner (vs. Not married) & $70.4 \%$ & $76.7 \%$ & N.S. & 0.80 & $0.29-2.23$ \\
\hline Employed (vs. Not employed) & $56.8 \%$ & $58.8 \%$ & N.S. & 0.78 & $0.28-2.16$ \\
\hline$\geq \$ 50,000$ income per year (vs. $<\$ 50,000$ per year) & $17.3 \%$ & $35.0 \%$ & $<0.05$ & 2.82 & $0.90-8.86$ \\
\hline Have health insurance (vs. None) & $67.9 \%$ & $83.5 \%$ & $<0.05$ & 3.04 & $0.98-9.48$ \\
\hline \multicolumn{6}{|l|}{ Smoking history } \\
\hline Age started smoking & 16.9 years \pm 5.2 & 17.9 years \pm 5.5 & N.S. & 1.02 & $0.95-1.09$ \\
\hline \multicolumn{6}{|l|}{ Acculturation } \\
\hline Percent lifetime in U.S. ${ }^{c}$ & $27.9 \pm 21.1$ & $32.2 \pm 18.3$ & N.S. & 0.99 & $0.96-1.01$ \\
\hline $\begin{array}{l}\text { Language used with friends, at family gatherings, } \\
\text { and neighbors, three item index }(\alpha=0.64 \text {, range: } \\
5 \text { "mostly Tagalog" to } 15 \text { "mostly English") })^{\mathrm{d}}\end{array}$ & $8.2 \pm 2.1$ & $9.0 \pm 1.6$ & $<0.01$ & 1.31 & $1.01-1.69$ \\
\hline \multicolumn{6}{|l|}{ Cognitive } \\
\hline $\begin{array}{l}\text { Knowledge of health effects of smoking score, } \\
8 \text { item index }(\alpha=0.64 \text {, range } 0 \text { "less knowledge" } \\
\text { to } 8 \text { "more knowledge") }\end{array}$ & $7.2 \pm 1.1$ & $7.5 \pm 0.9$ & N.S. & 1.13 & $0.77-1.68$ \\
\hline $\begin{array}{l}\text { Positive beliefs on physical and social consequences } \\
\text { of smoking, } 12 \text { item index }(\alpha=0.85 \text {, range: } 0 \\
\text { "less positive" to } 12 \text { "more positive") }\end{array}$ & $5.2 \pm 3.1$ & $2.5 \pm 2.6$ & $<0.001$ & 0.69 & $0.59-0.81$ \\
\hline \multicolumn{6}{|l|}{ Social environment } \\
\hline Most of their friends smoke (vs. None/Some/Half) & $42.3 \%$ & $20.4 \%$ & $<0.01$ & 0.37 & $0.16-0.87$ \\
\hline Others in household smoke (vs. None) & $34.6 \%$ & $26.5 \%$ & N.S. & 1.04 & $0.39-2.82$ \\
\hline \multicolumn{6}{|l|}{ Physical environment } \\
\hline $\begin{array}{l}\text { Household smoking completely prohibited } \\
\text { (vs. Not prohibited) }\end{array}$ & $29.6 \%$ & $61.2 \%$ & $<0.001$ & 3.82 & $1.52-9.62$ \\
\hline \multicolumn{6}{|l|}{$P>0.05$} \\
\hline \multicolumn{6}{|c|}{${ }^{\text {a }}$ Significant difference between categorical variables tested using $X^{2}$-test, and continuous variables tested using $T$-test } \\
\hline \multicolumn{6}{|l|}{ b Confidence interval for logistic regression } \\
\hline \multicolumn{6}{|c|}{ ' Percent lifetime is a calculated variable based on the respondents' self-report of their current age and age of immigration to the U.S } \\
\hline \multicolumn{6}{|c|}{$\begin{array}{l}\text { d Language index: each of the three language items was scaled from } 1 \text { (mostly Tagalog) to } 5 \text { (mostly English); thus, when combined into a } \\
\text { 3-item index, the scores range from } 5 \text { (mostly Tagalog which suggest less acculturation) to } 15 \text { (mostly English which suggest more acculturation) }\end{array}$} \\
\hline
\end{tabular}

significant when we controlled for other sample characteristics in a multivariate analysis. Contrary to previous studies $[4,5]$, we did not find an independent association between any of the demographic items and successfully quitting to smoke. This suggests that perhaps there are factors that mediate or moderate the influence of demographics to smoking cessation behavior.

We found that Filipino immigrant men whose social circle consists predominantly of Filipinos (based on the language use) and whose friends are mostly smokers are less likely to be successful in quitting smoking. This may be partly explained by the Filipino value of pakikisama, which means getting along with peers in order to avoid conflict. A recent study of smoking behavior of Filipinos in the Philippines found that social relations play a major role in one's decision to initiate or quit smoking [10]. To preserve pakikisama, Filipinos engage in activities that their peers are involved in. Thus, if Filipinos are in frequent company of smoking peers, they tend to initiate or continue smoking so as not to disappoint their peers as directed by the pakikisama principle [10]. Our study suggests that pakikisama may be operating in several of our respondents' decision to continue smoking; that is, when Filipino smokers are with fellow Filipino smokers, it is difficult to 
quit smoking because refusing an offer of cigarette in their social circle can risk breaking the relationship formed by pakikisama.

Our finding that Filipino immigrant men with negative beliefs on benefits of smoking are more likely to successfully quit smoking is similar to findings in other ethnic groups $[2,5,6]$. From a public health point of view, this finding is encouraging because cognitive factors, such as beliefs, can be addressed in a smoking cessation program through education, media campaigns, and counseling.

Finally, similar to prior research in other racial/ethnic groups [6], having a complete prohibition of smoking in the household was one of the strongest correlates of successful quitting in our sample. This suggests that a complete home smoking ban is accepted among many Filipino immigrants and that contingencies are in place to protect the health of non-smokers.

Our study has two major limitations. It analyzed crosssectional data, limiting our ability to make causal inferences. Additionally, the data collected were from a convenience sample, limiting our ability to make generalizations. Despite these limitations, our findings are useful guides for designing tobacco control intervention for Filipinos in the U.S.

\section{Conclusion}

Our findings suggest that the establishment and enforcement of home smoking bans can assist in cessation intervention for Filipino immigrant men, as this was the strongest correlate in our study. It may also be beneficial to design an intervention that encourages smokers to invite their smoking friends to participate so they can provide reinforcement for each other through pakikisama. Additionally, smoking cessation programs for this group should focus on changing the smokers' social environment and perceptions regarding the positive consequences of smoking in a way that is culturally sensitive and appropriate, and taking into account the different levels of acculturation.
Acknowledgments This research was supported by a grant from the Cancer Research and Prevention Foundation. GMG was also supported by University of Alaska Anchorage Department of Health Sciences, and AEM was also supported by U01CA114640 in completion of the manuscript. The authors thank the Filipino men and the organizations that participated in the study, as well as the interviewers for recruiting and interviewing patients.

Open Access This article is distributed under the terms of the Creative Commons Attribution Noncommercial License which permits any noncommercial use, distribution, and reproduction in any medium, provided the original author(s) and source are credited.

\section{References}

1. U.S. Census Bureau Census: Demographic profile highlights: general demographic characteristics. Geographic area, California, Fact Sheet 2000 [cited 2006 August 24]; 2000. Available from: http://factfinder.census.gov.

2. Maxwell AE, Bernaards CA, McCarthy WJ. Smoking prevalence and correlates among Chinese- and Filipino-American adults: findings from the 2001 California health interview survey. Prev Med. 2005;41(2):693-9. doi:10.1016/j.ypmed.2005.01.014.

3. Cockburn M, Deapen D, editors. Cancer incidence and mortality in California: trends by race/ethnicity, 1988-2001. Los Angeles: Los Angeles Cancer Surveillance Program, University of Southern California; 2004.

4. Hymowitz N, Cummings KM, Hyland A, Lynn WR, Pechacek TF, Hartwell TD. Predictors of smoking cessation in a cohort of adult smokers followed for five years. Tob Control. 1997;6(Suppl 2): S57-62. doi:10.1136/tc.6.suppl_2.S57.

5. Lee CW, Kahende J. Factors associated with successful smoking cessation in the United States, 2000. Am J Public Health. 2007; 97(8):1503-9. doi:10.2105/AJPH.2005.083527.

6. Ji M, Hostetter CR, Melbourne H, Irvin V, Song YJ, Lee J, et al. Smoking cessation patterns and predictors among adult Californians of Korean descent. Nicotine Tob Res. 2005;7(1):59-69. doi: $10.1080 / 14622200412331328493$.

7. Ma GX, Tan Y, Toubbeh JI, Su X, Shive SE, Lan Y. Acculturation and smoking behavior in Asian-American populations. Health Educ Res. 2004;19(6):615-25. doi:10.1093/her/cyg070.

8. Maxwell AE, Garcia GM, Berman BA. Understanding tobacco use among Filipino-American Men. Nicotine Tob Res. 2007; 9(7):769-76. doi:10.1080/14622200701397890.

9. SPSS Inc.SPSS. Chicago, IL; 2002.

10. Garcia GM. To smoke or not to smoke: understanding smoking and nonsmoking behaviors among Filipinos. Dissertation, University of California, Los Angeles; 2008. 